\title{
Industry Payments and New Breast Cancer Screening Technology Use
}

J Gen Intern Med 36(5): 1440-2

DOI: $10.1007 / \mathrm{s} 11606-020-440-9$

(c) Society of General Internal Medicine 2020

\section{INTRODUCTION}

Digital breast tomosynthesis (DBT) is a newer breast imaging modality that may have improved sensitivity and specificity for breast cancer screening compared with 2D mammography. ${ }^{1}$ The U.S. Preventive Services Task Force and American Cancer Society, however, have not recommended for or against the use of DBT, citing insufficient evidence. ${ }^{2,3} \mathrm{Nev}$ ertheless, DBT use has increased. ${ }^{4}$

Industry payments to physicians have been linked to preferential use of specific drugs, but comparatively little is known about the relationship between industry payments and use of imaging technologies. ${ }^{5,6} \mathrm{We}$ assessed the association between industry payment receipt and subsequent use among individual radiologists and within radiology groups.

\section{METHODS}

We used the federal CMS Open Payments database to identify DBT product-specific, general industry payments (non-research, non-ownership) to radiologists between 2014 and 2016. We also used the CMS Medicare Provider Utilization and Payment file to quantify radiologists' claims for screening mammography, including DBT, between 2015 and 2017. We identified mammography, including DBT, using the, CPT/ HCPCS billing codes 77057, G0202, and 77063. We linked Open Payments data to radiologists' claims in the subsequent calendar year based on first name, last name, and zip code, similar to other studies. ${ }^{5}$ We also identified groups of radiologists based on shared street address and zip code.

We used logistic regression to evaluate the relationship between receipt of DBT-specific industry payments and DBT use in the subsequent calendar year. We also evaluated whether radiologists who did not personally receive a payment but practiced in a group with someone who did were more likely to use DBT. Multivariable models were adjusted for radiologist sex, state, mammogram volume, and group practice size, with standard errors clustered by group. We

Electronic supplementary material The online version of this article (https://doi.org/10.1007/s11606-020-05771-9) contains supplementary material, which is available to authorized users.

Received February 25, 2020

Accepted March 6, 2020

Published online May 28, 2020 expressed results as adjusted percentages using predicted probabilities.

This study was deemed exempt by the Human Investigation Committee of Yale School of Medicine. Analyses were performed in Stata (version 14.0; StataCorp). A 2-sided $P<.05$ was considered statistically significant.

\section{RESULTS}

In $2015,13,083$ radiologists billed for screening mammograms, of whom $137(1.0 \%)$ received a DBT-specific payment in the previous year. In 2016, 184 (1.4\%) of 12,837 radiologists received payment in 2015; in 2017, 203 (1.6\%) of 12,683 radiologists received payment in 2016. Characteristics of payments, radiologists, and groups are summarized in Table 1.

In adjusted analyses, in $2015,63 \%$ of radiologists who received a payment in 2014 used DBT compared with $36 \%$ of those who did not receive a payment $(P<.001)$. By 2017 , $83 \%$ of radiologists who received payment in the prior year used DBT, compared with $66 \%$ of those who did not $(P$ $<.001)$. Among radiologists who did not personally receive payment in the previous year but were in a group with someone who did, $47 \%$ used DBT in 2015 compared with $37 \%$ of radiologists who were in a group where no one received payment $(P=.005)$. These figures were, respectively, $59 \%$ and $54 \%(P=.13)$ in 2016 and $77 \%$ and $68 \%(P=.002)$ in 2017 (Fig. 1).

\section{DISCUSSION}

We observed a consistent association between industry payment receipt and DBT use among radiologists. A robust literature has described the relationship between industry payments and physician prescribing patterns. ${ }^{5,6}$ Our results build upon this literature, suggesting that industry payments may be relevant to other kinds of medical practice. Further, we found that payments may influence practice within groups and thus may ultimately touch a much larger number of clinicians. Indeed, although only a small number of radiologists received a payment, 4-7 times as many were in a group with someone who did.

Our study has limitations. Most importantly, we cannot determine causality from this study design, although the broader literature linking payments to behaviors makes causality plausible. ${ }^{5,6}$ Second, only a small number of radiologists accepted an industry payment and such payments, even if causal, are not the predominant factor driving DBT adoption. Lastly, our method for matching radiologists to payments and 
Table 1 DBT Product-Specific General Industry Payment Characteristics, Individual Radiologist Characteristics, and Group Characteristics

\begin{tabular}{|c|c|c|c|c|c|c|}
\hline Payment characteristics & 2014 & & 2015 & & 2016 & \\
\hline Total value, $\$$ & 628,198 & & 351,191 & & 862,059 & \\
\hline Total number of payments & 242 & & 320 & & 804 & \\
\hline Median value (IQR), \$ & $576(96-2,000)$ & & $174(45-641)$ & & $75(22-317)$ & \\
\hline Range, \$ & $7-28,865$ & & $4-40,000$ & & $1-25,483$ & \\
\hline Individual characteristics & 2015 & & 2016 & & 2017 & \\
\hline & Payment* & No payment & Payment & No payment & Payment & No payment \\
\hline Number of radiologists & 137 & 12,946 & 184 & 12,653 & 203 & 12,480 \\
\hline $\begin{array}{l}\text { Mean 2D mammogram } \\
\text { volume }\end{array}$ & 608 & 433 & 652 & 445 & 779 & 450 \\
\hline Group characteristics** & 2015 & & 2016 & & 2017 & \\
\hline & $\begin{array}{l}\text { Payment in } \\
\text { group }\end{array}$ & $\begin{array}{l}\text { No payment in } \\
\text { group }\end{array}$ & $\begin{array}{l}\text { Payment in } \\
\text { group }\end{array}$ & $\begin{array}{l}\text { No payment in } \\
\text { group }\end{array}$ & $\begin{array}{l}\text { Payment in } \\
\text { group }\end{array}$ & $\begin{array}{l}\text { No payment in } \\
\text { group }\end{array}$ \\
\hline Number of radiologists & 897 & 9908 & 950 & 9568 & 833 & 9529 \\
\hline Number of groups & 101 & 1885 & 105 & 1835 & 123 & 1819 \\
\hline $\begin{array}{l}\text { Mean number of radiologists } \\
\text { in group }\end{array}$ & 10 & 5.3 & 10.4 & 5.2 & 8.2 & 5.2 \\
\hline
\end{tabular}

*Payment status refers to payment in the previous calendar year

** "Payment in group" column refers to radiologists who did not personally receive a DBT product-specific payment in the previous year but were in a group with a radiologist who did, while "No payment in group" column refers to radiologists who did not personally recieve a payment and were in a group where no one else received a DBT product-specific payment in the previous year. Only groups where size $>1$ radiologist were included $D B T$, digital breast tomosynthesis; IQR, interquartile range
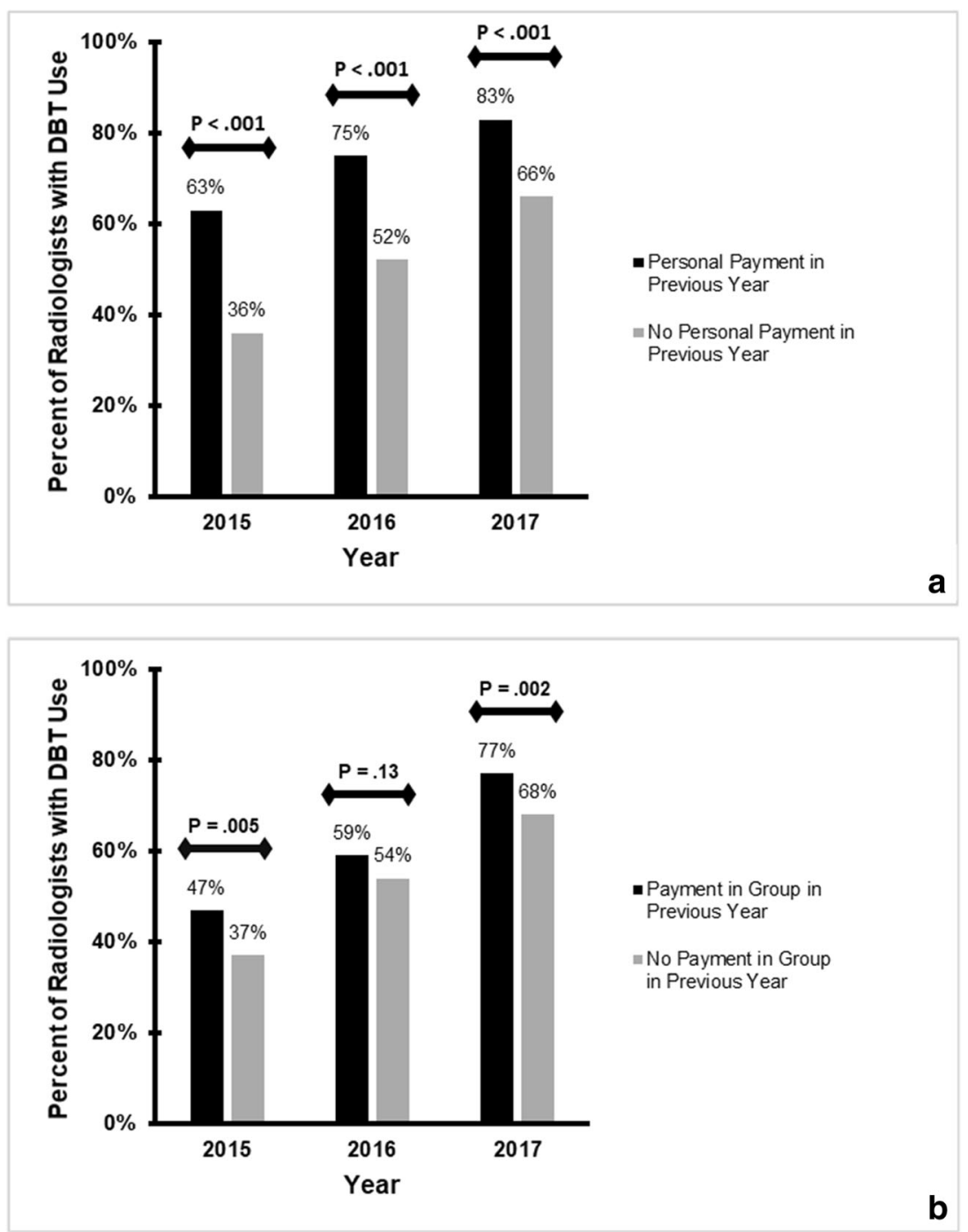

Figure 1 Radiologist DBT use by individual and group payment status. Panel a, DBT use among radiologists, grouped according to receipt of DBT product-specific payment in previous year. Panel b, DBT use among radiologists who did not personally receive DBT product-specific payment in the previous year, grouped according to whether another radiologist in the practice received payment. Results indicate predicted probabilities from logistic regression. $D B T$, digital breast tomosynthesis. 
grouping radiologists may be subject to error; however, these errors would tend to bias results toward the null.

Our results have important policy implications. Current policies for payment reporting focus on individuals. However, many specialties, including radiology, practice in groups and make group decisions about practice standards and technological investments. As group practice arrangements become more common and complex, the implications of conflict of interest for groups may deserve greater attention.

Kunal C. Potnis, $B S^{1}$

Cary P. Gross, $M D^{2,3}$

Ilana B. Richman, $\mathrm{MD}^{2,3}$

${ }^{1}$ Yale School of Medicine, New Haven, CT, USA

${ }^{2}$ Department of Medicine, Yale School of Medicine, New Haven, CT, USA

${ }^{3}$ COPPER Center, Yale School of Medicine, New Haven, CT, USA
Corresponding Author: Ilana B. Richman, MD; Department of Medicine, Yale School of MedicineNew Haven, CT, USA

Funding Information Funding for this work was provided by KL2 TR001862 (Richman).

\section{Compliance with Ethical Standards:}

Conflict of Interest: Dr. Richman receives salary support from the Centers for Medicare and Medicaid to develop health care quality measures outside of the submitted work. Dr. Gross has received research grants from NCCN/Pfizer-Astra Zeneca, Genentech, and Johnson and Johnson and travel funding from Flatiron Health outside of the submitted work.

\section{REFERENCES}

1. Marinovich ML, Hunter KE, Macaskill P, Houssami N. Breast Cancer Screening Using Tomosynthesis or Mammography: A Meta-analysis of Cancer Detection and Recall. J Natl Cancer Inst. 2018;110:942-9.

2. Siu AL, Force USPST. Screening for Breast Cancer: U.S. Preventive Services Task Force Recommendation Statement. Ann Intern Med. 2016;164:279-96.

3. Oeffinger KC, Fontham ET, Etzioni R, et al. Breast Cancer Screening for Women at Average Risk: 2015 Guideline Update From the American Cancer Society. JAMA. 2015;314:1599-614.

4. Richman IB, Hoag JR, Xu X, et al. Adoption of Digital Breast Tomosynthesis in Clinical Practice. JAMA Intern Med. 2019.

5. DeJong C, Aguilar T, Tseng C-W, Lin GA, Boscardin WJ, Dudley RA. Pharmaceutical Industry-Sponsored Meals and Physician Prescribing Patterns for Medicare Beneficiaries. JAMA Intern Med. 2016;176:1114-22.

6. Mitchell AP, Winn AN, Dusetzina SB. Pharmaceutical Industry Payments and Oncologists' Selection of Targeted Cancer Therapies in Medicare Beneficiaries. JAMA Intern Med. 2018;178:854-6.

Publisher's Note Springer Nature remains neutral with regard to jurisdictional claims in published maps and institutional affiliations. 